\title{
Apparent enhanced response to the induction of sister chromatid exchange by mitomycin $\mathrm{C}$ in myotonic dystrophy
}

\author{
VIJAYALAXMI*, A E H EMERY†, AND H J EVANS* \\ From*the MRC Clinical and Population Cytogenetics Unit, and $\dagger$ the Department of Human Genetics, \\ University of Edinburgh, Western General Hospital, Edinburgh
}

SUMMARY The spontaneous and mitomycin C (MMC) induced sister chromatid exchange (SCE) frequencies were examined in five adults with myotonic dystrophy (MD). There was no significant difference in the spontaneous incidence of SCE between MD patients and controls. However, a significantly enhanced response to the induction of SCE by MMC was observed in three of the five MD patients who were severely affected, while no such enhancement was observed in the other two mildly affected cases. These results suggest that the raised response may be a secondary consequence associated with disease progression. No differences were observed between the proliferating rate in vitro of lymphocytes of severe and mild cases of MD and controls, but the severe cases showed a significant increase in the proportion of $\mathrm{T}$ cells in peripheral blood. It is suggested that the observed enhanced response to MMC may reflect an increase in the proportion of a more sensitive subset of $\mathrm{T}$ cells in the peripheral blood.

Myotonic dystrophy (MD) is an autosomal dominant disease associated with myotonia, muscle atrophy, neural abnormalities, cataract, frontal baldness, and various endocrinopathies especially gonadal insufficiency. There are no significant racial or geographical variations in prevalence, which ranges from 2.4 to 5.5 per 100000 population in different parts of the world. ${ }^{1}$ Though there has been no systematic study of a possible association between MD and early onset of malignancies, there have been a few isolated reports of MD being associated with chronic granulocytic leukaemia, ${ }^{2}$ Hodgkin's disease, $^{3}$ fibrosarcoma (D Parry, 1976, personal communication), and leukaemia of undetermined type (A E H Emery, unpublished data).

A number of autosomal recessive disorders which result in early neuronal degeneration and predisposition to malignant disease are also associated with defective DNA repair and/or an enhanced incidence of spontaneous or mutagen-induced chromosomal aberrations or sister chromatid exchanges. ${ }^{4-6}$ Cytogenetic studies on blood lymphocytes of children with congenital MD, and their affected mothers, have not revealed any major chromosome anomalies or raised spontaneous aberration frequencies. ${ }^{7}$ In the present paper we Received for publication 24 June 1981 report on the spontaneous incidence of SCE in blood lymphocytes of five adults with $\mathrm{MD}$ and on the response of these cells to SCE induction by mitomycin C (MMC).

\section{Patients, materials, and methods}

Peripheral blood samples were obtained from five adult MD patients, three female and two male, and from five age and sex matched healthy controls. The patients' ages ranged from 23 to 41 years. Three were categorised as being severely affected (cases 1,2 , and 3 ) and two mildly affected (cases 4 and 5). Cases 1 and 2 were sibs, but none of the other cases was related and none was in hospital or receiving any drug therapy. Peripheral blood was collected in heparinised tubes and coded, and lymphocytes were separated by gravity sedimentation at $37^{\circ} \mathrm{C}$ for 1 to 2 hours. Serum and red blood cells were used for other clinical investigations. Separate cultures were set up using approximately 1 to $1.5 \times 10^{6}$ lymphocytes in $10 \mathrm{ml}$ RPMI 1640 medium supplemented with $20 \%$ fetal calf serum, $1 \%$ reconstituted phytohaemagglutinin, $1 \%$ glutamine, $100 \mathrm{U}$ penicillin, $100 \mu \mathrm{g}$ streptomycin, and $25 \mu \mathrm{mol} / 1 \quad 5-$ bromodeoxyuridine. They were immediately treated with mitomycin C (Kyowa, Japan, dissolved in distilled water) at fixed concentrations of $10^{-8}$, 
$3 \times 10^{-8}$, and $10^{-7} \mathrm{~mol} / 1$ and incubated in the dark at $37^{\circ} \mathrm{C}$ for 72 hours. Then $0.5 \mathrm{ml}$ of a $10^{-5} \mathrm{~mol} / 1$ colchicine solution was added to each $10 \mathrm{ml}$ culture (final concentration of $5 \times 10^{-7} \mathrm{~mol} / 1$ colchicine) for the final 2 hours. Lymphocytes were collected, treated with $75 \mathrm{mmol} / 1$ potassium chloride, and fixed in 3:1 methanol acetic acid. Air-dried preparations were made and stained for differential chromatid staining. ${ }^{8}$ The prepared slides from both patients and controls were randomised, coded, and then scored 'blind', so that the observer had no knowledge of the source of the material. From each culture, 20 metaphases in second division were examined to record the frequency of SCE.

\section{Results and discussion}

The results, in the form of dose response curves, are summarised in figs 1 and 2 and they show that the spontaneous incidence of SCE did not differ between MD patients and controls. Exposure to MMC resulted in a dose dependent increase in SCE in

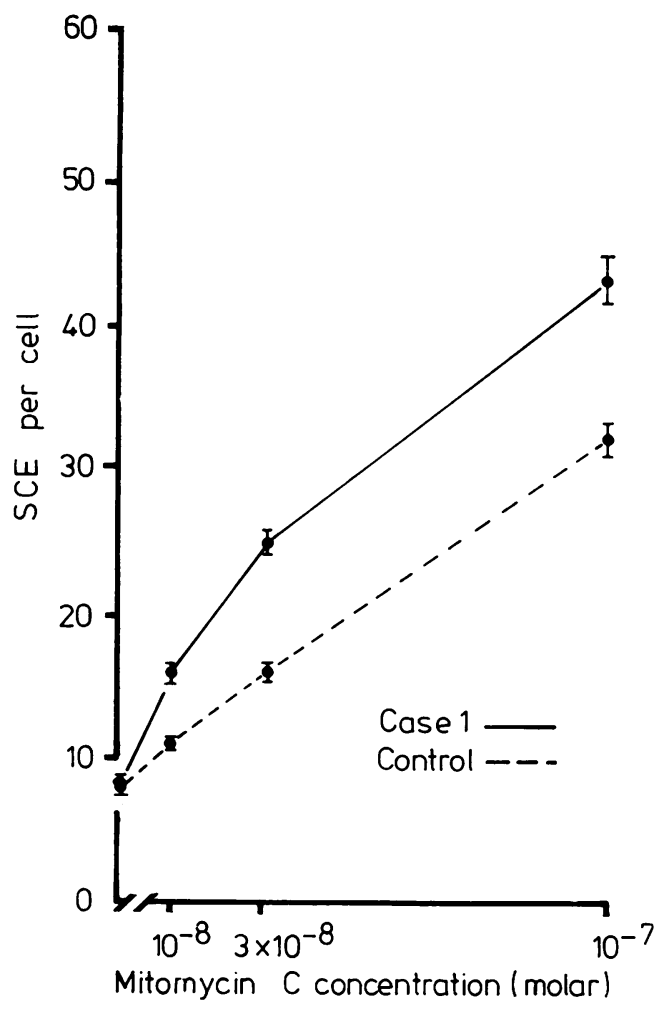

(a) cells from all cases and were some five to six times higher than baseline levels following exposure at $10^{-7} \mathrm{~mol} / 1$. Of particular interest was the finding that in three of the five MD patients the response to SCE induction was significantly enhanced relative to the controls. It transpired that these were the three severely affected patients. The responses of cells from the mildly affected cases did not differ from controls.

The enhanced MMC response in cells from the severely affected cases amounted to a consistent increase over controls of around $30 \%$. The absence of any difference between cases 4 and 5 (mildly affected) and controls suggests that the observed raised response is a secondary consequence associated with disease progression and that MD is not a condition characterised by an enhanced response to mutagen-induced chromosome damage. One obvious possibility to account for the difference in response between cells from severely as opposed to mildly affected MD patients is that there may be a different spectrum of lymphocytes present in the blood samples from the two kinds of patient.

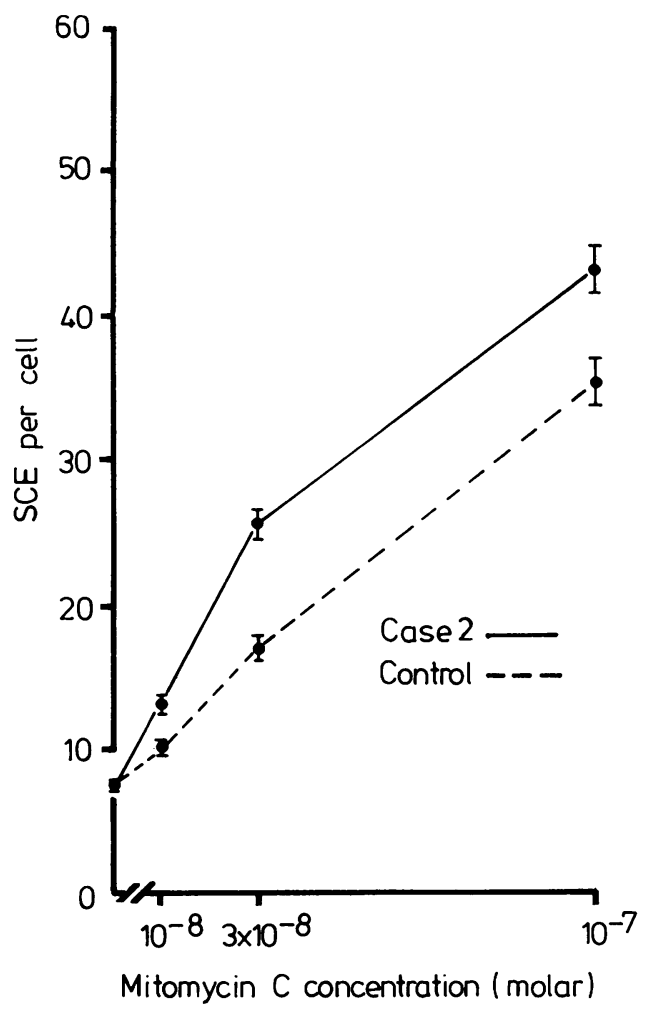

(b)

FIG 1a, b, c Incidence of SCE in the three severely affected MD cases (cases 1, 2, and 3) and in relevant controls after exposure to mitomycin $C$ 


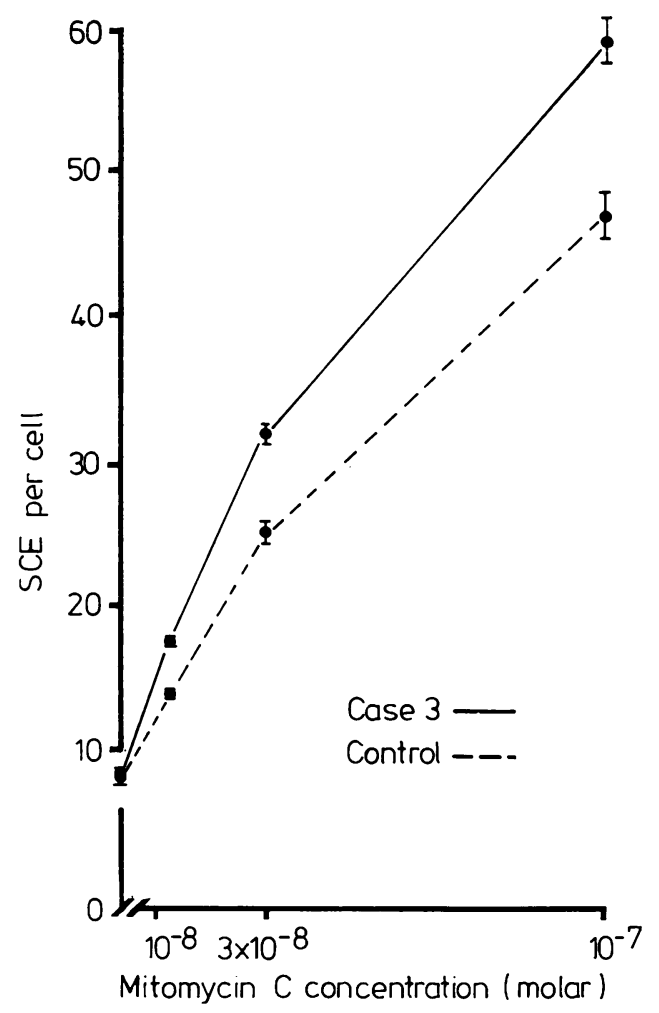

(c)

There is evidence that spontaneous and mutageninduced SCE frequencies may be slightly higher in T lymphocytes proliferating at slower rates, 910 and although no obvious difference in PHA response between blood samples was noted in the present experiments, this seemed a possible explanation of our findings. To examine this possibility the proportions of cells in their first, second, and third mitosis were determined from 100 cells in each sample scored. The distinction between these three mitotic divisions can be unambiguously ascertained by virtue of their BUdR staining reactions and the results are summarised in the table. The data in the table reveal no diminution in the proportions of cells in the later mitotic phases between severely and mildly affected cases, so that no differences in cell proliferation rate were evident between these two kinds of patient. We are therefore left with the possibility that the different responses to SCE induction by MMC between these patients may reflect other possible differences such as, for example, between sub-sets of the $T$ cell populations in the patients. The proportions of $\mathrm{T}$ lymphocytes, deter-

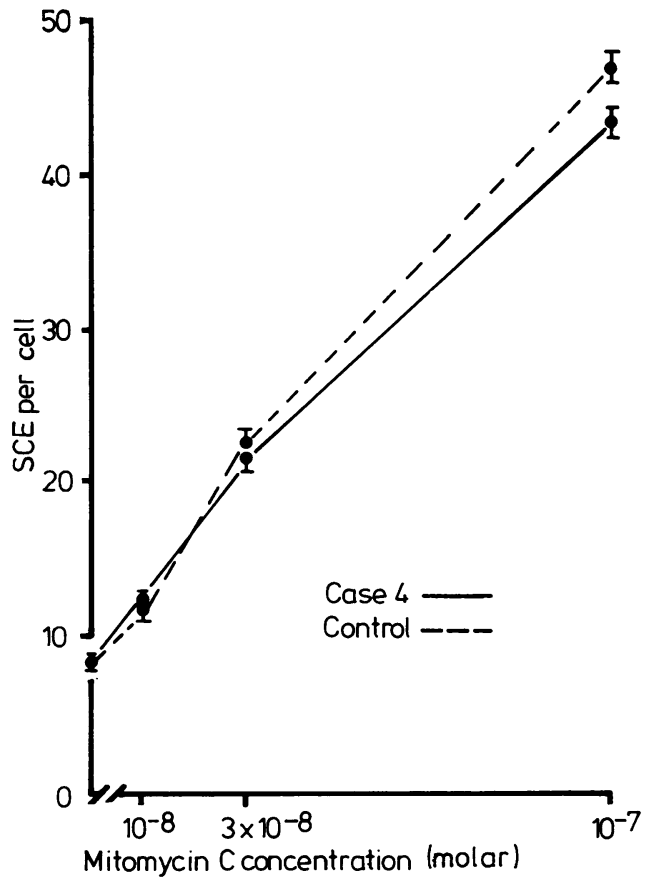

(a)

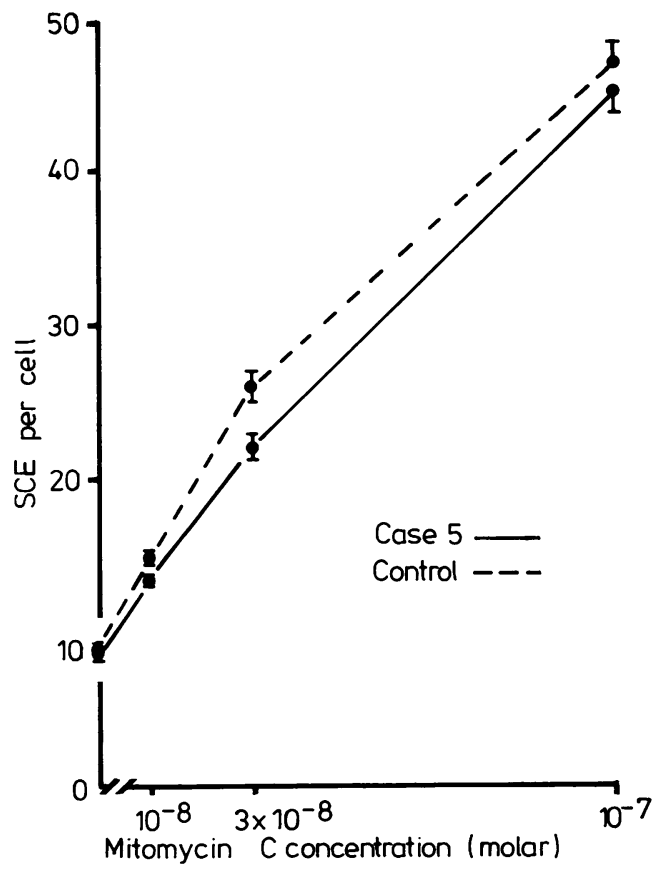

(b)

FIG $2 \mathrm{a}, \mathrm{b}$ Incidence of SCE in the two mildly affected cases (cases 4 and 5) and in relevant controls after exposure to mitomycin $C$ 
TABLE Percentage of cells* in first $(I)$, second $(I I)$, and third (III) mitosis in culture

\begin{tabular}{|c|c|c|c|c|c|}
\hline $\begin{array}{l}\text { Mitomycin } C \\
\text { concentration } \\
(\text { mol/l) }\end{array}$ & $\begin{array}{l}\text { Mitotic division } \\
\text { in culture }\end{array}$ & $\begin{array}{l}\text { Control } \\
\text { (mean from } \\
3 \text { subjects) }\end{array}$ & $\begin{array}{l}\text { Severely affected } M D \\
\text { (mean from cases } \\
1,2 \text { and } 3 \text { ) }\end{array}$ & $\begin{array}{l}\text { Control } \\
\text { (mean from } \\
2 \text { subjects) }\end{array}$ & $\begin{array}{l}\text { Mildly affected } M D \\
\text { (mean from cases } \\
4 \text { and } 5)\end{array}$ \\
\hline \multirow[t]{3}{*}{ Control } & I & $29 \cdot 3$ & $28 \cdot 0$ & $20 \cdot 0$ & $31 \cdot 0$ \\
\hline & II & $52 \cdot 3$ & $50 \cdot 3$ & $51 \cdot 0$ & $56 \cdot 0$ \\
\hline & III & $18 \cdot 3$ & $21 \cdot 7$ & 29.0 & $13 \cdot 0$ \\
\hline \multirow[t]{2}{*}{$10^{-8}$} & I & $31 \cdot 3$ & $22 \cdot 0$ & $22 \cdot 5$ & $34 \cdot 0$ \\
\hline & II & $40 \cdot 7$ & $50 \cdot 7$ & $51 \cdot 0$ & $47 \cdot 0$ \\
\hline \multirow[t]{3}{*}{$3 \times 10^{-8}$} & I & $28 \cdot 3$ & $26 \cdot 7$ & $34 \cdot 5$ & $25 \cdot 5$ \\
\hline & II & $52 \cdot 0$ & $44 \cdot 7$ & $51 \cdot 0$ & $48 \cdot 0$ \\
\hline & III & $19 \cdot 7$ & $28 \cdot 7$ & $14 \cdot 5$ & $26 \cdot 5$ \\
\hline \multirow[t]{3}{*}{$10^{-7}$} & I & $42 \cdot 0$ & $42 \cdot 6$ & $37 \cdot 5$ & $34 \cdot 0$ \\
\hline & II & $51 \cdot 0$ & $49 \cdot 3$ & $53 \cdot 0$ & $50 \cdot 0$ \\
\hline & III & $7 \cdot 0$ & $8 \cdot 0$ & 9.5 & $16 \cdot 0$ \\
\hline
\end{tabular}

* 100 cells were scored per subject for each sample

mined by rosetting with sheep RBCs, in two of the severely affected cases ( 1 and 3 ) were $88 \%$ and $86 \%$ and in one of the mild cases (case 4) $77 \%$. The values obtained in the severely affected patients are significantly above normal values obtained in our laboratory $(65$ to $75 \%)$. The possibility remains, therefore, that the enhanced SCE response of lymphocytes of the severe cases of MD may be the result of an increase in the proportion of a more sensitive $\mathbf{T}$ lymphocyte population in these patients. There is also the possibility that some of the other manifestations of the disease might be the result of a reduction in B cells and this is currently under investigation.

\section{References}

1 Harper PS. Myotonic dystrophy. Philadelphia: Saunders, 1979.

2 Fraumeni JF, Chabner BA, Li FP, Carbone PP. Myotonic dystrophy and leukemia. JAMA 1969;208:696.

3 Michalak JC, Dibella NJ. Exacerbation of myotonia dystrophica by vincristine. $N$ Engl J Med 1976;295:283.

4 Arlett CF, Lehman AR. Human disorders showing increased sensitivity to the induction of genetic damage. Ann Rev Genet 1978;12:95-115.

5 Moshell AN, Barret SF, Tarone RE, Robbins JH. Radiosensitivity in Huntington's disease: implications for pathogenesis and presymptomatic diagnosis. Lancet 1980;i:9-11.

6 Evans HJ. Sister chromatid exchanges and disease states in man. In: Wolff S, ed. Sister chromatid exchange. New York: Wiley (in press).

7 Conner G. In: Myotonic dystrophy. Philadelphia: Saunders, 1979: 218-9.

8 Perry PE, Wolff S. New giemsa method for differential staining of sister chromatids. Nature 1974;251:156-8.

9 Ockey CH. Differences between 'spontaneous' and induced sister-chromatid exchanges with fixation time and their chromosome localization. Cytogenet Cell Genet 1980;26:223-35.

10 Lindblad A, Lambert B. Relation between sister chromatid exchange, cell proliferation and proportion of $\mathbf{B}$ and $T$ cells in human lymphocyte cultures. Hum Genet $1981 ; 57: 31-4$.

Requests for reprints to Professor H J Evans, MRC Clinical and Population Cytogenetics Unit, Western General Hospital, Crewe Road, Edinburgh EH4 2XU. 